\title{
Culture and Public Goods: The Case of Religion and the Voluntary Provision of Environmental Quality
}

\author{
Ann L. Owen* \\ Julio R. Videras \\ Hamilton College
}

August 2006

\begin{abstract}
Using data from approximately 11,000 individuals in 14 different OECD regions, we find that culture, as expressed by religious beliefs, generates public goods contributions. We characterize individuals into systems of religious beliefs using latent class analysis and find that some types of beliefs influence pro-environment behaviors and attitudes, even after controlling for religious affiliation, political views and activism, and sociodemographic characteristics. The results indicate that the system of religious beliefs matters but not being religious per se. We find a role for beliefs that is separate from social capital accumulated via membership in church groups and church attendance. Finally, we make a methodological contribution by showing that the use of latent class analysis to describe systems of beliefs yields more meaningful interpretations than the standard approach of dummy variables for specific beliefs.
\end{abstract}

*We are grateful for financial support from the Blue Moon Fund. Pragyan Pradhan provided excellent research assistance. We thank Jennifer Thacher, Robert Turner, and Steve Wu for helpful comments. 


\section{Introduction}

Although much is understood about the role of formal institutions such as markets and codified rules in coordinating the interaction of economic agents, policymakers and social scientists are becoming aware of the importance of informal institutions for the design and implementation of successful economic policies. In the last few years, the economics literature has exploded with theoretical and empirical investigations linking informal institutions to the functioning of the economic system. This literature has shown that incorporating culture, social norms, and measures of human interactions into economic theory and empirics increases our understanding of how the impact of economic fundamentals depend on the type and strength of informal institutions (see, for example, Iyigun and Owen, 2006; Guiso, Sapienza, and Zingales, 2006; Temple and Johnson, 1998; or Knack and Keefer, 1997).

This paper furthers this line of thinking by investigating how religion, a critical part of an individual's culture, influences economic behavior and, in particular, the voluntary provision of environmental quality. Using a sample of approximately 11,000 individuals in 14 OECD regions, we present evidence that decomposes the influence of religion into an effect attributable to religious beliefs and an effect attributable to the social capital associated with participation in religious activities. We find that the type of religious beliefs individuals hold influences economic behavior even after controlling for religious affiliation and participation, political views and activism, and sociodemographic characteristics. Interestingly, the results suggest that it is not being religious per se that matters but the system of personal beliefs the individual holds.

In order to isolate the influence of religious beliefs from the effects attributable to religious affiliation and social capital related to religious participation, we treat religious beliefs as a multi-dimensional construct and apply latent class analysis to create a typology of belief systems. Then we estimate probit models of the likelihood of engaging in pro-environment behaviors and attitudes using the posterior probabilities of latent class membership, church attendance, membership in a church group, and affiliation as explanatory variables. We show that the latent class approach to characterize religious beliefs provides meaningfully different and richer interpretations of the results than those based on standard approaches used in the literature. Furthermore, because we use latent 
class analysis to characterize belief systems, our approach to linking behavior to beliefs vs. religious participation or social capital is more convincing.

Although recent work has revitalized the importance of norms and traditions, the idea that culture and religion are related to economic outcomes has long philosophical roots. In the Wealth of Nations, Adam Smith viewed religion as a way to enhance one's human capital. As discussed in Anderson (1988), Smith observed two ways in which religion could affect economic behavior. First, religious beliefs provided a system of "internalized monitoring” that encouraged individuals to behave in ways that benefit society. Second, belonging to a religious group awards an individual social capital and this group membership signals merit to potential employers. In line with Smith's observation about beliefs and their effect on behavior, Max Weber (1930) attributed European prosperity to a Protestant work ethic.

Many researchers have now adopted the view that religion can influence economic choices and outcomes and include some control for religion in empirical analyses. As did their predecessors, current researchers find a role for religion either through its shaping of a value system that affects behavior or through the social capital link associated with sharing beliefs, values, and engaging in common activities with a well-defined group of individuals. ${ }^{1}$ For example, La Porta et al. (1999) and Easterly and Levine (2003) hypothesize that religion shapes attitudes toward formal institutions and consequently economic policies and outcomes. These authors include the percentage of the population that belongs to several religious affiliations as a control in explaining economic growth. Some authors have explored the role that specific religious beliefs or participation in group worship can have on economic growth and individual attitudes. McCleary and Barro (2006) use attendance at religious services and belief in Hell and Heaven to explore the effect of these factors at the country level on development. Guiso, Sapienza, and Zingales (2003) use attendance, belief in God, and being raised religiously at home to examine the relationship between religious factors and preferences over the economic system. Recent work has also focused on the relationship between culture or human capital and the development of growth-promoting institutions (see, for example,

\footnotetext{
${ }^{1}$ Of course, in theory, holding religious beliefs does not have to imply involvement with a group, however, as Iannaccone (1998) points out, in practice, religious behavior almost always involves group association.
} 
Guiso, Sapienza, and Zingales, 2006; Tabellini, 2005; Glaeser, La Porta, Lopex-deSilanes, and Schleifer, 2004; or Greif, 1994). Finally, social scientists have extensively studied philanthropic behavior such as making charitable donations or volunteering and found that religious people are more likely to make monetary donations and volunteer their time to church-related and non-church related activities (Brooks, 2003; Putnam, 2000).

We contribute to this literature by examining whether religion influences the use of natural and environmental resources through the voluntary provision of the public good of environmental quality. There are several reasons why religion may influence pro-environment behaviors and attitudes. Culture can be particularly relevant in understanding attitudes and behaviors toward the natural environment. Religious traditions and movements include world views, ethical precepts, and spiritual elements that shape perceptions about the natural environment and can act as guiding principles regarding how our acts and choices affect nature. Second, to the extent that religious values are found to foster charitable behavior, they might also be associated with greater public goods contributions in the form of pro-environment behavior. Finally, church and community groups or more informal social networks formed by religious affiliation might encourage contributions to the public good either directly through their activities or indirectly through a sense of connectedness created by these memberships. ${ }^{2}$ Our work decomposes the influence of religion into effects attributable to the system of religious beliefs a person holds and those attributable to religious affiliation and social capital related to religious participation.

The findings regarding the reasons why individuals engage in pro-environment behavior can aid the design of public policy aimed at increasing these contributions. This research can also shed light on how cultural factors can influence efforts to implement sustainable development programs. In addition, our research contributes to the rapidly growing body of knowledge that recognizes the importance of the cultural environment in which individuals make economic decisions and highlights the importance of treating culture as a complex multi-dimensional construct. We argue that latent class analysis is a

\footnotetext{
${ }^{2}$ Since Lynn White (1967) hypothesized the Judeo-Christian tradition is responsible for current environmental problems, many empirical studies have tested this hypothesis with inconclusive results.
} 
more appropriate way of incorporating complex belief systems into empirical analyses of economic behavior and then provide empirical evidence that shows that this measurement of religiosity leads to more accurate and nuanced conclusions than the use of ad hoc indicators.

The rest of the paper proceeds as follows: Section 2 introduces the methodology that we use to construct a typology of religious beliefs, Section 3 presents the results of the latent class analysis, and Section 4 presents the data and results of the models estimating the likelihood of pro-environment behaviors. Section 5 concludes.

\section{Methodology: Latent Class Models of Religious Beliefs}

Previous authors have allowed religious beliefs to affect economic behavior through the use of a few dummy variables that are assumed to summarize these beliefs (see, for example, Brooks and Lewis, 2001; Guiso, et. al., 2003; McCleary and Barro, 2006). Instead, we employ latent class analysis to examine the associations between religious beliefs and to identify classes of people by their sets of beliefs. Compared to the ad hoc choice of a single belief and to entering multiple beliefs simultaneously (a practice that assumes the effect of a particular belief is independent of the effects of other beliefs), latent class analysis allows us to take into account the fact that individual's religious beliefs are in fact related and interact with each other to form an interdependent set of beliefs.

We use data from the World Values Survey (WVS) that include eight dichotomous variables for religious beliefs. There are $2^{8}=256$ possible unique response patterns of these dichotomous variables. In a sample of 11,248 individuals from OECD countries for whom we have responses to all eight indicators, we observe 196 response patterns. $^{3}$ This large number of observed unique responses suggests that there is substantial heterogeneity in the sample and that it might be unrealistic to presume that one or two measures of religious beliefs can properly characterize and differentiate among respondents. Alternatively, if we were to consider each observed response pattern a unique type of religiosity, then we would need to include 195 dummy variables in

\footnotetext{
${ }^{3}$ Twenty patterns account for 75 percent of the observations while we need 42 patterns to account for 90 percent of the observations and 78 patterns for approximately 96 percent of the sample.
} 
regression models explaining economic behavior. Importantly, people may differ in their degree of certainty about their beliefs and about what they mean when they say that they hold certain beliefs. For example, Bishop (1999) has analyzed the trends in poll statistics regarding belief in God in America and concluded that although a very high percentage of individuals claim to believe in God, it is unclear whether individuals believe in a similar God or believe with the same degree of certainty.

Our strategy is to consider religiosity an unobserved latent variable and to treat religious beliefs as indicators (with errors) of that unobserved latent construct. Because latent class models are probability-based, the analysis accounts for errors in the responses and for the uncertainty of classification. In our application, we are able to reduce the 196 observed response patterns down to eleven distinct latent classes and separate out groups of individuals who, for example, believe in God but have very different belief systems.

Although latent class analysis (LCA) has been applied to several social issues (see, for example, Patterson et al. 2002; and Biemer and Wiesen, 2002), it is still a fairly novel methodology in the economics literature (see Boxall and Adamowicz, 2002; Greene and Hensher, 2003; Provencher and Bishop, 2004; Clark, Etile, Postel-Vinay, Senik and Van der Straeten, 2005; Scarpa and Thiene, 2005; Morey, Thacher, and Breffle, 2006). Both on theoretical and practical grounds, however, latent class analysis is a promising approach to the study of social and cultural capital.

Our approach is to estimate LCA models to classify individuals into classes according to their belief systems. From these results, we compute posterior probabilities of class membership and include these probabilities in probit models estimating the likelihood of engaging in several pro-environment behaviors and expressing proenvironment values. In this manner, we examine whether different belief systems have different effects on public goods contributions.

Latent class analysis can be described by letting the vector $\mathrm{Y}=\left(Y_{1}, Y_{2}, \ldots, Y_{T}\right)$ denote the response variables or indicators and $X$ denote a latent categorical variable with $q$ classes. In our case, we have 8 dichotomous questions from the WVS about religious beliefs (belief in God, Hell, Heaven, the Devil, life after death, sin, a soul, and importance of religion in the respondent's life) so $T=8$. We observe the contingency table with $2^{8}=256$ possible response patterns. The latent class model assumes the 
observed contingency table is a mixture of tables generated by $q$ unobserved distinct classes. The goal is to "unmix" the sample and identify the distinct classes.

Estimation is based on the idea that the probability of obtaining a specific response pattern is the average probability of the response pattern given each class, weighted by the prior probability of class membership (Magidson and Vermunt, 2003). Let $i=1, \ldots, I$, denote the respondents. For each individual we observe the response to a set of seven questions denoted $k=1, \ldots, 8$. Then, $Y_{i k}=1$ if the individual responds "yes" to question $k$, and $Y_{i k}=0$ otherwise. The response pattern of an individual is represented by the vector, $Y_{i}$. Under a generalized finite-mixture model, we assume a finite number of latent religious systems denoted $s=1, \ldots, \mathrm{S}$. The discrete latent variable $X$ represents the religious system class. Then:

$$
P\left(Y_{i}\right)=\sum_{s=1}^{s} P\left(X_{i}=s\right) \times \prod_{k=1}^{8} P\left(Y_{i k} \mid X_{i}=s\right) .
$$

The conditional probability that an individual in latent class $s$ responds "yes” to indicator $k$ is modeled as a logit equation:

$$
P\left(Y_{i k}=1 \mid X_{i}=s\right)=\frac{\exp \left(\beta_{k s}\right)}{1+\exp \left(\beta_{k s}\right)},
$$

where $\beta_{k s}$ is a free parameter.

Latent class analysis determines the smallest number of latent classes that account for the observed relationships among response variables. As is traditionally done, we start by assuming only one class - which is equivalent to assuming mutual independence among response variables - and then increase the number of classes if the independence model does not fit the data adequately. In determining the number of latent classes among the models that fit the data adequately, we use the Bayesian information criterion (BIC) based on the model's log-likelihood. ${ }^{4}$ The models are fitted using Maximum Likelihood methods and the results yield the conditional response probabilities for each

\footnotetext{
${ }^{4}$ The Bayesian information criterion is calculated as $-\mathrm{LL}+\mathrm{Ln}(\mathrm{N}) * \mathrm{P}$, where -LL is the model's Loglikelihood, $\mathrm{P}$ is the number of parameters, and $\mathrm{N}$ is the number of observations. We also computed the Akaike information criterion (AIC $=-2 \mathrm{LL}+2 * \mathrm{P}$ ) and the consistent Akaike information criterion (CAIC $=$ $\left.2 \mathrm{LL}+[\operatorname{Ln}(\mathrm{N})+1]^{*} \mathrm{P}\right)$. The AIC favors models with larger number of classes, a tendency that increases with the sample size. The CAIC favors models with fewer classes but this under-fitting declines with sample size. In our application, both the BIC and the CAIC indicate a model with eleven classes is the best among the models that fit the data.
} 
belief. These conditional probabilities are then used to compare and define the classes. Using Bayes rule, we calculate posterior membership probabilities that are then used in a subsequent regression analysis.

\section{Results for Latent Class Models}

In this section we first present the indicators that we use to classify individuals into religious belief systems. Then we estimate LCA models. Our goals in this section are to describe the data we use to characterize religious beliefs, justify our selection of the specific latent class model we use, and describe the resulting classes.

We take our data from the third wave of the WVS, which was conducted during the 1995-1997 time period. We focus our analysis on individuals in the OECD countries represented in the WVS. The WVS also contains data from several non-OECD developing countries. However, we found that incorporating individuals from these countries into the latent class analysis introduces too much heterogeneity into the sample and we were unable to find a global maximum of the likelihood function for those models that fit the data. Our difficulty in classifying individuals from many different cultures by religious beliefs underscores the importance of treating beliefs as a complex, multidimensional construct. ${ }^{5}$ Thus, in this part of our analysis, we pool all the individuals from the 14 OECD regions, with the goal of identifying the belief systems in the sample and assessing a probability of holding each belief system for each individual.

The WVS, wave 3, contains questions about seven religious beliefs: belief in God, Heaven, Hell, the Devil, the soul, life after death, and sin. In addition, the survey asks individuals how important religion is in their lives. We include this indicator in order to be able to separate individuals who claim to hold some beliefs but are not engaged with those beliefs. ${ }^{6}$ These eight indicators are fairly general and although we should expect

\footnotetext{
${ }^{5}$ The countries in our analysis are Australia, Germany, Finland, Japan, Mexico, Norway, Spain, Sweden and the U.S. The WVS reports data separately for East and West Germany as well as Andalusia, Basque Country, Galicia and Valencia because many of these regions may be culturally different than others in the same country (for example, these regions have their own language). We follow the WVS treatment of these regions and use separate dummy variables for these regions in the probit analysis described in Section 4.

${ }^{6}$ The latent class model in equation 1 assumes that, conditional on class membership, responses to each indicator are independent. We relax this assumption by modeling local dependencies through the use of an interaction term between pairs of indicators (Magidson and Vermunt, 2003). In particular, we include local
} 
affiliation, education, and income to be related to a person's belief system, we note that specific beliefs or combinations of these beliefs cannot be uniquely assigned to concrete religious affiliations or socio-economic status. It is precisely for this reason that we believe the use of latent class models is warranted and that we expect religious beliefs might have an autonomous role on explaining behaviors and attitudes.

We use a sample of 11,248 individuals for whom we observe responses to all eight indicators. The top part of Table 1 presents summary statistics for the indicators. Fifty-six percent of the respondents say that religion is personally important to them. The median number of beliefs people hold is 5; 3 and 7 beliefs are the 25- and 75-percentile, respectively, and the range goes from zero to all seven beliefs. The most common belief is the belief in God and the belief that people have a soul, 83 and 79 percent of the respondents, respectively. The two least common beliefs are belief in Hell and belief in the Devil, with less than half of the sample stating these beliefs. Although Pearson's Chisquare tests strongly reject the null hypotheses of no association between each pair of beliefs, there is a substantial degree of heterogeneity in how these seven beliefs are combined.

As we noted earlier, we observe 196 unique response patterns in our sample. Interestingly, this heterogeneity in belief patterns is also present within religious affiliations. For example, among the 5,223 respondents who identify themselves as Catholic we observe 147 unique patterns, among 3,325 Protestants we observe 140 unique patterns, and 123 unique patterns among the respondents who do not subscribe to any affiliation. Therefore, the purpose of this first stage is to characterize individuals according to their belief systems only. In the second stage of our analysis, when we estimate probit models of the likelihood of pro-environment behaviors, we control for religious affiliation, membership in a religious group, and attendance at services. In this way, we are able to investigate whether religious beliefs have an autonomous role on behavior after controlling for affiliation and social capital accumulated through participation.

dependencies between beliefs in Hell and Heaven, beliefs in Hell and the Devil, and beliefs in Heaven and the Devil. Descriptive statistics show that responses to these indicators are highly correlated. 
Table 2 presents goodness-of-fit statistics for latent class models. Among the models that fit the data (based on the bootstrap p-value of the Pearson statistic), the eleven class model has the lowest BIC. ${ }^{7}$ Although a seven-class model has the lowest BIC, the bootstrap p-value of the Pearson statistic indicates that the seven-class model does not fit the data. ${ }^{8}$ The probabilities of holding each belief conditional on class membership for the 11-class model are presented in Table 3. We calculate class sizes using modal probability assignment, that is, each individual is assigned to the latent class for which she has the largest posterior probability.

Class 1 contains 36 percent of the sample and has very high response probabilities to all eight indicators. In contrast, Class 3, with 9.5 percent of the sample, could be described as the "secular class," with low response probabilities for each indicator. Class 2 is the second largest class, with 13 percent of the sample. Individuals in this class are characterized by high probabilities of a belief in God, the afterlife, and a soul, but relatively low response probabilities to the remaining beliefs. Individuals in Class 5 have relatively low probabilities for all beliefs except belief in the soul. Individuals in Class 5 are similar to individuals in class 2, but their belief in the soul is not accompanied by high probabilities of belief in God or an afterlife. Similarly, individuals in Class 4 are similar to individuals in Class 1, except individuals in Class 4 do not share the high probabilities of beliefs in the Devil and Hell. Individuals in Class 6 have a high probability for belief in God, but low probabilities for all other beliefs, while individuals in Class 7 have high probabilities of believing in God and in sin and moderate probabilities for belief in the soul and an afterlife. Although the individuals in classes 8 through 11 are also distinguished by the patterns of beliefs they hold, we note that these individuals are a small part of our overall sample.

The results in Table 3 emphasize the complexity of religious beliefs. For example, individuals in classes 1, 2, 4, 6, 7, 8 and 10 all have a high probability of claiming a belief in God. However, as the pattern of responses to the remaining beliefs reveals, a belief in God can be accompanied by a wide range of religious beliefs. In the

\footnotetext{
${ }^{7}$ To address the issue of local maxima we estimated several times each model using 10,000 starting values. The bootstrap p-values of the Pearson statistic are calculated using 500 replications.

${ }^{8}$ When we examine the class structure created by the seven class model, we find that the seven classes are a subset of the eleven classes we use. Although our classes 8 through 11 are relatively small, goodness of fit statistics indicate that they are necessary in order to accurately describe the patterns in the data.
} 
next section, we show that incorporating this complexity into models that predict proenvironment behavior allows for meaningfully different and richer conclusions about how beliefs affect behavior.

The distribution of religious affiliation and socio-economic characteristics across latent classes shows that we cannot use these characteristics to explain completely religious beliefs. For example, only 14 percent of the individuals assigned to Class 3 , the "secular class," identify themselves as Catholic while 56 percent of the individuals assigned to Class 1, the "strong believers" class, identify themselves as Catholic. That the majority of individuals in Class 1 are Catholic is not a surprising finding, however, religious affiliation is not synonymous with the belief systems individuals hold since there are Catholics across all latent classes. We find that individuals in Class 1 are closer to the extreme political right than individuals in Class 3 or Class 5, (the averages of selfplacement in the political spectrum are 5.6 for Class 1 and 4.8 for Class 3 and Class 5). Almost 19 percent of individuals in Class 1 have no formal education while the rates of individuals with no formal education in Class 3 and Class 5 are 11 and 8 percent, respectively. Finally, almost 30 percent of people in Class 1 are in the bottom 10 percentile of the income distribution but in Class 3 and Class 5 the proportion of individuals in the bottom 10 percentile are markedly lower at 15 and 14 percent, respectively. Finally, we also estimate OLS models of each posterior probability on socio-demographic controls, other religious controls, and country dummies. The Rsquared ranges from .35 (for the probability of being assigned to Class 1) to .02 (for the probability of being assigned to Class 9 and Class 11). These statistics suggest that although socio-economic factors are related to the type of belief system a person holds, a large combination of factors cannot totally explain the posterior probabilities. Thus, it is reasonable to expect that the posterior probabilities of latent class membership can have an autonomous role even after controlling for religious affiliation and socio-economic variables. $^{9}$

\footnotetext{
${ }^{9}$ It is possible to estimate latent class models that include socio-demographic characteristics as determinants of class membership (by including covariates into equation 2). However, our goal in this paper is not to explain latent class membership but to investigate whether the type of belief system a person holds influences economic behavior after controlling for other relevant factors.
} 


\section{Pro-Environment Behaviors and Attitudes}

In this section, we use the characterization of individuals into the latent classes described in the previous section to determine how religious beliefs affect proenvironment behaviors and attitudes. We estimate probit models that predict proenvironment behavior and attitudes, using the posterior probabilities of membership in each class as explanatory variables. Specifically, for individual $i$ in country $j$, we estimate

$$
P\left(E_{\text {NVIRON }}=1\right)=\Phi\left(\beta_{0}+\beta_{1} \text { BELIEF }_{i j}+\beta_{2} \text { RELIGIOUS }_{i j}+\beta_{3} X_{i j}+\alpha_{j}\right)
$$

where ENVIRON is one of four pro-environment behaviors or attitudes, BELIEF is a vector of probabilities of membership in each latent class for that individual, RELIGIOUS is a vector of several other behaviors/characteristics that are associated with religious beliefs, and $X$ is a vector of socio-demographic controls. ${ }^{10} \alpha$ is a vector of region dummy variables that controls for omitted region characteristics. When estimating equation 3, we calculate cluster-adjusted robust standard errors that account for withinregion correlation and heterocedasticity. Below, we describe in more detail the data we use to estimate equation 3 and then present our results.

\subsection{Data}

\section{Measures of pro-environment behavior and attitudes}

The third wave of the WVS contains a series of questions about activities that individuals have undertaken in the past 12 months "out of concern for the environment." We construct three different dummy variables from the response to this question. These activities are: choosing household products that "you think are better for the environment," (PRODUCT), deciding “for environmental reasons to reuse or recycle something rather than throw it away” (RECYCLE), and “contributed to an environmental

\footnotetext{
${ }^{10}$ As an alternative to using the posterior probabilities of membership in each class for BELIEF, we could use a series of dummy variables in which the class with the highest posterior probability for each individual is coded as 1 and the other classes are 0 . Using posterior probabilities is preferable because it allows us to exploit within-class heterogeneity since we do not have the same degree of certainty about how to classify each individual based on the individual's responses. The dummy variable approach yields identical qualitative results but the $p$ values of some coefficients are higher. Nonetheless, inference regarding the autonomous role of some beliefs systems still holds.
} 
organization (CONTRIBUTE). ${ }^{11}$ Each of these variables is coded as 1 if individuals have done the activity in the last 12 months, 0 otherwise. These activities differ in their potential effects on environmental quality and can have different monetary as well as symbolic implications for households. Therefore, a priori we do not expect our measures of religiosity and other socio-economic factors will have the same point estimates across all pro-environment behaviors. That said, we do believe that buying environmentallyfriendly products or recycling are more comparable behaviors than contributing to an environmental organization for two reasons. First, recycling or buying specific products does not require trust in voluntary organizations. ${ }^{12}$ Second, contributing to an environmental organization requires an explicit monetary cost and no direct benefit.

In addition to these three behaviors, we examine individual attitudes toward environmental protection with a fourth variable, PROTECT. PROTECT is equal to 1 if the individual claims that the statement "Protecting the environment should be given priority, even if it causes slower economic growth and some lost jobs" is "closer to your point of view" than the statement "Economic growth and creating jobs should be the top priority, even if the environment suffers to some extent.” Although one well-known result of the environmental valuation literature is that attitudes and intentions do not necessarily imply behaviors, we examine this expression of pro-environment attitudes to investigate whether or not religious beliefs might help to advance changes in environmental practices and policies.

\section{Controls for Religion}

In addition to the vector of posterior probabilities of membership in each belief class derived from the latent class analysis, we control for religious affiliation and religious participation. There are good reasons to treat beliefs, affiliation, and participation separately. First, there are differences between nominal religious affiliation and

\footnotetext{
${ }^{11}$ We also considered a variable that indicates whether individuals have tried to conserve water for environmental reasons. However, although water conservation does contribute to the public good, individuals may also receive personal benefit from this behavior through reduced fees or water charges. Therefore, the benefits of this behavior are both private and public. As might be expected, when we estimate the likelihood of water conservation we get results that are consistent with those presented, but weaker.

${ }^{12}$ See Owen and Videras (2006) for an analysis of how trust in the environmental movement affects an individual's contribution to environmental organizations.
} 
theological involvement and conviction. Among individuals who report to be Protestant, for example, we might expect to find different levels of engagement with the theological principles of Protestantism as well as different degrees to which those principles shape a person's economic behavior. A second related issue is that there can be substantial variability regarding values within specific traditions. For example, some individuals might choose to focus on a set of values of Christianity that promote an attitude of stewardship toward the biosphere while similarly convinced believers might ascribe to aspects of Christianity that encourage an attitude of dominance toward nature. ${ }^{13}$

Researchers have argued that some religious traditions include world views, rituals, and spiritual elements that can foster environmental protection, for example, Buddhism and Hinduism. The WVS classifies individuals into nine categories: Catholic, Protestant, Orthodox, Jewish, Muslim, Hindu, Buddhist, other affiliations, and no affiliation. However, in the OECD countries in our sample, we have very few observations for individuals who are Orthodox, Jewish, Hindu or Buddhist. Therefore, we collapse the nine categories to six dummy variables: Catholic, Protestant, Muslim, other Judeo-Christian affiliations (Jewish and Orthodox), other affiliations, and no affiliation (the omitted category). Importantly, religious affiliation is not synonymous with the belief systems individuals hold. Although the majority of Catholics are found in the "strong believer" class, there are Catholics in all other 10 latent classes and none of the classes consist of individuals in only one affiliation. This explains why we are able to find a role for beliefs that is independent of nominal affiliation and indicates that researchers can usually exploit the heterogeneity of values within standard classifications of religion.

We also control for religious practice. Putnam (2000, page 67) writes: "In part, the tie between religion and altruism embodies the power of religious values, $[\ldots]$ but the social ties embodied in religious communities are at least as important as religious beliefs per se in accounting for volunteerism and philanthropy. Connectedness, not merely faith, is responsible for the beneficence of church people.” To control for connectedness, in the

\footnotetext{
${ }^{13}$ Biels and Nilsson (2005) argue that researchers who test the White hypothesis regarding the influence of Judeo-Christian religions on current environmental problems arrive at contradictory or inconclusive results because specific religious affiliations can include values that have different implications for individuals' attitudes and behavior toward the natural environment.
} 
second set of models we include a dummy variable that equals 1 if the respondent goes to church at least once a week (CHURCHGOER) and a dummy variable that equals 1 if the respondent participates actively in church-organized activities (CHURCHACTIVE). By including these variables in addition to beliefs, we isolate the effects of an individual's religious beliefs from the effects of group association that accompany religious participation.

\section{Socio-Demographic Controls}

A person's religion can be related to her political views and attitudes toward civic behavior. In order to control for the effects of religious beliefs on pro-environment behaviors we include three variables that measure attitudes toward free riding, political identification, and political engagement.

We control for political preferences with an index that indicates a respondent's self-placement in the left-right political spectrum, RIGHT. RIGHT takes on the value of " 1 " if the person places herself in the extreme left and the value of " 10 " if the person places herself in the extreme right. ${ }^{14}$ We would expect this variable to have a negative coefficient since the pro-environment movement is often identified with left-leaning political agendas. Political activism may also be related to religious values and environmental action. We construct an index of political engagement by adding 1 if the individual has ever (i) signed a petition, (ii) joined in boycotts, (iii) attended lawful demonstrations, (iv) joined unofficial strikes, and (v) occupied buildings or factories. The index POLITICAL can take on the values 0 to 5 , with five indicating the highest level of political activism.

Attitudes towards free-riding behavior may also affect an individual's decision to make public goods contributions. To construct a variable that measures individuals' attitudes towards free-riding behavior, we follow Knack and Keefer (1997) who use data from the World Values Survey to formulate an indicator of social responsibility by adding responses to questions regarding whether certain free-riding behaviors can ever be

\footnotetext{
${ }^{14}$ A more appropriate treatment of this index might be to create ten dummy variables. However, given that the specifications are fairly complex, include several dummy variables already, and that we are not per se interested in the estimate of this control, we include the variable as a scale and abstain from interpreting the magnitude of the coefficient estimate.
} 
justified. For each of the following five free-riding behaviors, we add a 1 to CIVIC each time the respondent states that behavior is never justifiable. The behaviors examined are: (i) "Claiming government benefits to which you are not entitled;" (ii) "Avoiding a fare on public transport;" (iii) "Cheating on taxes if you have a chance;" (iv) "Someone accepting a bribe in the course of their duties," and (v) "Buying something you knew was stolen.” Thus, CIVIC takes on values of 0 to 5 , with 5 being associated with the highest levels of civic cooperation. We interpret a 1-unit increase in CIVIC as a person's willingness to impose on herself an additional constraint on opportunistic behavior.

Finally, we include age and age squared, gender, dummy variables for education levels, the relative place in the income distribution in that individual's country (i.e., the quintile), and country-specific intercepts.

The bottom part of Table 1 presents summary statistics for the main variables used in our analysis. The statistics indicate that the average age of individuals in our sample is 43 , slightly over half of the sample is female, and respondents to the survey placed themselves in the middle of the political spectrum. ${ }^{15}$ The most common proenvironment behavior is recycling, with 75 percent of the sample responding that they have recycled in the last year, followed by using environmentally-friendly products at 67 percent. Contributing to environmental organizations is much less common, with only 18 percent of the sample responding that they have done this in the last year. A large part of our sample is Catholic (47 percent), while the second most common religion is Protestantism (30 percent). There are very few Jewish, Orthodox, and Muslim respondents in this multi-country OECD sample, but a notable portion of the respondents (17 percent) do not claim an affiliation with any organized religion. In the next section, we use the data described in Table 1 in conjunction with the results of our latent class analysis to examine the determinants of pro-environment behavior and attitudes.

\subsection{Results}

Table 4 presents the results of the models estimating the three pro-environment behaviors and attitude with socio-demographic controls, religious participation and

\footnotetext{
${ }^{15}$ The median value for RIGHT is also 5. Mean and median values for CIVIC and POLITICAL are also similar with a median value for CIVIC of 4 and a median value of POLTICAL of 1 .
} 
affiliation, and country dummies. ${ }^{16}$ Although we find some evidence that older people are more likely to recycle and purchase environment-friendly products at a decreasing rate, age is not related to making contributions to environmental groups or proenvironment attitudes. We find similar results for an individual's levels of civic cooperation (CIVIC): the more civic-minded an individual is the more likely she recycles and buys environment-friendly products but willingness to limit free-riding does not have a statistically significant effect on contributions and attitudes. Being female and more politically active (POLITICAL) are associated with greater probabilities of engaging in pro-environment behaviors and attitudes while not completing university-level education and leaning toward the right on the political spectrum are associated with lower probabilities. Not surprisingly, income has the most significant effects on making contributions to environmental organizations, with the probability rising with income. These controls have very similar effects in all other specifications we discuss later and we do not continue to report them in the text. ${ }^{17}$

The models in Table 4 also include religious affiliation and participation. Consistent with the literature, we do not find strong effects of affiliation on the likelihoods of engaging in pro-environment behaviors and attitudes. ${ }^{18}$ In addition, we find no evidence that attending church frequently (CHURCHGOER) affects proenvironment behavior or attitudes. On the other hand, consistent with the argument in Putnam (2000), we find some evidence that involvement in religious groups influences pro-environment behavior. Individuals who are active in church groups are more likely to recycle and also to contribute to environmental organizations.

In Table 5, we present the results for the models that include religious beliefs as measured by posterior probabilities of membership in each latent class. Because the posterior probabilities add to 1 for each individual, we omit Class 3 to avoid perfect

\footnotetext{
${ }^{16}$ In comparing the number of observations in Table 1 to the number used in the estimations in Tables 4 through 8 , one will note that we lose several observations. This is due to patterns of missing data that do not allow us to use all the observations for which we have information about religious beliefs. To gauge whether or not these missing observations were influencing our results, we imputed missing data with the average values for that variable in the sample and estimated equation 4 with the full sample and obtained similar results qualitatively and in terms of statistical significance.

${ }^{17}$ Any results not reported in detail in the paper are available from the authors upon request.

${ }^{18}$ Whitford and Wong (2006) find comparable effects of affiliation on environmental sustainability at the country level.
} 
multicollinearity. Although labeling the latent classes can sometimes be misleading, it is reasonable to term Class 3 the "secular class" since individuals in this class have the lowest probabilities for each indicator of beliefs. By omitting Class 3, we test the null hypothesis that increasing the probability that an individual is classified in a class other than the "secular class" has no effect on the likelihood of engaging in pro-environment behaviors and attitudes.

A first interesting result from this table is that the coefficients on the religious controls (affiliation, being active in church groups, and being a frequent churchgoer) barely change by the inclusion of the posterior probabilities of class membership, suggesting that the belief systems can have an effect on behavior that is independent of the variables typically used to measure religiosity. In addition, the probabilities of latent class membership enter significantly in several ways in these four specifications. High probabilities of membership in classes 2, 4 and 5 are associated with increased probabilities of purchasing environmentally friendly products, recycling and willingness to protect the environment, while higher probabilities of membership in classes 2 and 4 make it more likely that an individual will make a contribution to an environmental organization.

The magnitudes of the effects of religious beliefs are notable. Using the marginal effects associated with the estimations reported in Table 5, we calculate the change in the probability of purchasing environment-friendly products for a "typical" person in each class relative to a "typical" individual in the "secular class". We define a typical person in our sample as female, 43 years old, in the second lowest quintile of the income distribution, with high school education, Catholic who is not an active member of a church group and who does not attend church services once a week or more, with median levels of CIVIC, POLITICAL, and RIGHT. A "typical” person who belongs to Class 4 with a probability of 1 has an estimated probability of buying environmentally friendly products that is 10.5 percentage points higher than the probability of the same individual who belongs to Class 3 with probability of 1 . Belonging to Class 2 with a probability of 1 increases by 6.3 percentage points the probability of buying products that are good for 
the environment over the same individual in the "secular class", while belonging to Class 5 with a probability of 1 yields a 5.3 percent increase. ${ }^{19}$

Interestingly, we find evidence in one case only that individuals with high probabilities of being in Class 1, the "strong believer" class, act differently than the omitted class, the "secular class." Furthermore, their behavior cannot be distinguished statistically from those in Class 6, who have high probabilities of believing in God, but relatively low probabilities for the other beliefs. Individuals in both Class 1 and Class 6 show a higher likelihood of using environmentally friendly products, but the results for the other behaviors and attitudes are not statistically significant. The probabilities of membership in classes 8 through 11 enter significantly in a few of our estimations but it is difficult to emphasize these results as these classes represent only a very small fraction of the sample.

What do the belief systems with the largest effects on pro-environment behavior have in common? Classes 2, 4, and 5 have relatively high probabilities of believing in the soul, varying probabilities for belief in God, belief in sin, belief in an afterlife, and the importance of religion in their lives, and low probabilities for believing in Hell and the Devil. Thus, the increased probability of their pro-environment behaviors and attitudes may be traced to a belief system built around a more spiritual connection to the natural environment rather than through a promise of reward and punishment or through utility maximizing behavior in which the afterlife is considered (e.g., as in Azzi and Ehrenberg, 1975).

It is important to note that it is the system of beliefs that seems to generate proenvironment behavior, not any one specific belief. For example, individuals in Class 1 have a high probability of belief in the soul, but behave differently than individuals in classes 2, 4 and 5. Specifically, the probability of being in Class 1 enters only one estimation in Table 5 significantly, the prediction of purchasing environmentally-friendly products. And, even in that case, the coefficient on the probability of being in Class 1 is smaller than the coefficients on the probabilities of being in Classes 2, 4 , or $5 .{ }^{20}$

\footnotetext{
${ }^{19}$ The magnitudes of these effects are calculated for a "typical" individual in the U.S., however, we find very similar effects for "typical" individuals in other OECD countries.

${ }^{20}$ Wald tests that test the equality of the coefficients between Class 1 and Class 2, 4, and 5 reject the equality of the coefficient on Class 1 with each of the other 3 classes at p-values of .10 or less.
} 
Overall these results indicate that the type of religious beliefs a person holds explains economic behavior, however, being religious per se does not necessarily matter and religious affiliation does not seem to be associated with pro-environment activities and attitudes.

A potential caveat to the conclusions above is that the religious affiliation dummies we include in the probit equations might not capture the effect of membership in specific denominations within affiliations. For example, within a Protestant affiliation, Methodists and Baptists can have different propensities to hold the eight beliefs we analyze. If it were also the case that belonging to a Methodist church but not a Baptist church increased the probability of engaging in pro-environment activities, then we would be unable to uncover an effect of affiliation with our methods above, even though one existed. Instead, we could wrongly assign an effect to beliefs that should be attributed to institutionalized religion. In this case, if data on more narrowly defined denominations were available and there were enough observations to estimate the effects, we might find that the church to which the individual belongs does matter. Unfortunately, this data does not exist in the WVS.

We are still able to address this issue, however, by estimating the models in Table 5 , but restricting the sample to those individuals who do not attend church once a week or more (CHURCHGOER $=0$ ). It is much less likely that belonging to a church will affect behavior if individuals do not regularly attend the church. If the posterior probabilities of class membership are still significant in this restricted sample, then we have additional evidence to suggest that personal religious beliefs are important in determining proenvironment behavior independent of the effects of institutionalized religion. We present the results in Table 6. The estimates of the posterior probabilities are remarkably similar to the estimates from the full sample. Furthermore, in terms of statistical inference we derive the same overall conclusion: higher probability of membership in latent classes 2 , 4 , and 5 are related to increased likelihood of engaging in pro-environment behaviors and attitudes. ${ }^{21}$ Thus, even among individuals who do not attend church regularly, some

\footnotetext{
${ }^{21}$ There are only two differences regarding the posterior probabilities estimates' statistical significance. The coefficient of Class 4 in the RECYCLE equation and the coefficient of Class 5 in the PROTECT are significant at the 10 percent level in Table 5 but statistically insignificant in Table 6. Wald tests that test the equality of the coefficients between Class 1 and Class 2, 4, and 5 reject the equality of the coefficient on
} 
types of personal beliefs are positively associated with pro-environment behaviors and attitudes after controlling for affiliation and relevant socio-demographic factors. ${ }^{22}$ This finding corroborates our conclusions above that it is the type of religious beliefs and not religious affiliation that influences pro-environment behavior.

The results discussed above find a role for religious beliefs in influencing proenvironment behavior and attitudes, but the positive and significant coefficients on ACTIVECHURCH suggest a separate role for religious social capital in influencing behavior as well. In an attempt to learn if this effect is attributable to group association specific to religious activities or if it is more broadly attributable to general social capital, we estimate equation 3, adding an additional control variable, GROUPS, which is the number of civic or social organizations to which an individual belongs, excluding church and environmental groups. We note that this exercise would also help to control for omitted characteristics of the individuals that are related to joining social groups and also to engaging in pro-environment activities. These results are presented in Table 7.

The coefficients of GROUPS in Table 7 are positive and strongly significant in explaining the three types of pro-environment behaviors, indicating that pro-social characteristics are related to these public goods contributions. In spite of the fact that there is a strong correlation between social capital and pro-environment behavior, we find no evidence that this kind of social capital influences individual attitudes toward the environment. This result is not too surprising since expressing pro-environment attitudes does not necessarily imply engagement in environmental protection.

After including GROUPS, we find evidence that belonging to a church group has the same effect on this pro-environment behavior as belonging to other kinds of secular civic organizations. The coefficient on ACTIVECHURCH in the CONTRIBUTE

Class 1 with classes 4 and 5 in the PRODUCT equation. Not surprisingly, ACTIVECHURCH is not statistically significant in the restricted sample.

${ }^{22}$ We also estimated the models in Table 5 for the sample of individuals who are not affiliated with any religion. Remarkably, even in this smaller and more homogenous sample some types of religious beliefs are statistically associated with behaviors and attitudes. Higher probability of membership in Class 2 is positively related to contributions and stating willingness to protect the environment (p-values equal to .04 and .02, respectively). Higher probability of membership in Class 4 is positively related to purchasing environment-friendly products and stating willingness to protect the environment ( $\mathrm{p}$-values equal to .08 and .06 , respectively). These results are available from the authors upon request. 
estimation becomes insignificant and in the model for RECYCLE the coefficient of being an active member of a church group is very similar to the coefficient of GROUPS.

We address a final issue with our conclusions and note that although we include many socio-demographic and religious controls in equation 3 , it is still possible that we omit relevant individual characteristics. To assess the robustness of the results to the problem of omitted variables, we take advantage of the fact that we have two observations for each individual of pro-environment behaviors that follow similar processes (PRODUCT and RECYCLE) and estimate random-effects stacked probit models that account for unobserved individual heterogeneity. ${ }^{23}$ The results appear in Table 8. The first column presents results excluding GROUPS and the second column presents an estimation in which GROUPS is included. These results corroborate our earlier findings, with higher probabilities of being in classes 1, 2, 4, 5, and 6 generating a greater likelihood of engaging in the pro-environment behaviors. Furthermore, Wald tests reveal that the coefficients for membership in classes 4 and 2 are larger than those for Class 1, consistent with the stronger effects we found for these classes in our earlier results. $^{24}$ Interestingly, in these results, religious affiliation is statistically insignificant, suggesting that affiliation may proxy for omitted individual characteristics. Thus, the results of this exercise suggest that our original conclusions seem to be robust to omitted individual characteristics. ${ }^{25}$

\subsection{Comparison to other approaches}

We have argued that characterizing religious beliefs via latent class analysis is a more appropriate method to measure this complex set of values and provides results that yield richer and more sophisticated conclusions than the standard dummy variable approach. In this section we demonstrate this point by comparing our results to those obtained with the typical approach of characterizing religious beliefs by including one or more dummy variables for each belief. As mentioned earlier, this approach has been

\footnotetext{
${ }^{23}$ As we discuss earlier, making a contribution to a pro-environment organization is a fundamentally different behavior than recycling or buying environmentally-friendly products and we do not include it as one of the behaviors in the stacked-probit estimation.

${ }^{24}$ The p-values for the Wald tests determining if the coefficients are different are all less than .05 .

${ }^{25}$ This conclusion rests on the assumption made when estimating random effects models that the covariates are uncorrelated with the error term. Note that we cannot estimate a fixed-effect specification since individual characteristics are constant across choices.
} 
used extensively in the literature, but we argue that in term of the substantive insights to be derived from the analysis it has important limitations because it does not allow us to take into account combinations and interactions of the individual beliefs.

Table 9 presents results using the dummy variable approach for the three measures of pro-environment behaviors and the expression of pro-environment attitudes. We discuss first the results for PRODUCT and RECYCLE. Columns 1 and 3 of Table 9 include all of the religious controls we used earlier and a dummy variable indicating a belief in God. This dummy variable is positive and statistically significant in both columns 1 and 3, leading to the conclusion that a belief in God is positively related to pro-environment behavior. Our earlier results, however, suggest that this conclusion is misleading. For example, we find that individuals with high probabilities of being in Class 5 have low probabilities of stating a belief in God but higher probabilities of using environmentally-friendly products and recycling. In addition, both the log of the pseudolikelihood and the BIC statistic indicate that the latent class methods provide a better model fit than the model that includes a dummy for belief in God. From results not reported in the paper we arrive at similar conclusions if we include a few selected beliefs simultaneously such as belief in heaven and hell.

Similarly misleading conclusions might be drawn if the models included dummy variables for all beliefs as in columns 2 and 4 of Table 9. For example, the results in column 2 indicate that a belief in Heaven is negatively related to using environmentally friendly products. However, our earlier results show that individuals in Class 4 (with .84 posterior probability of believing in Heaven) are more likely to buy environment-friendly products. Similarly, the results in column 2 suggest that a belief in Hell is also negatively related to PRODUCT although using environmentally-friendly products was the one proenvironment behavior in which strong believers (with .90 posterior probability of believing in Hell) are more likely to engage. Most likely, the pattern of positive and negative coefficients that appears in both columns 2 and 4 are the result of multicollinearity and these results cannot be interpreted in any meaningful way. The results for making contributions to environmental organizations and for attitudes toward environmental protection over economic growth (columns 5 through 8 of Table 9) yield similar yet weaker conclusions. A belief in God does not yield statistically significant 
estimates in either column 5 or column 7 and when all beliefs are included as a series of dummy variables, a misleading pattern of positive and negative coefficients again appears. Using the latent class approach to describe types of belief systems allows a more meaningful interpretation of how religious beliefs and values affect economic behavior than a dummy variable approach. Due to collinearity, we cannot derive reliable insights from the models in Table 9. However, using the characterization from the latent class approach, we find that only some combinations of beliefs, those incorporating a belief of the soul but not necessarily a belief in God, generate higher likelihood of these outcomes relative to non-believers.

Before concluding, we should note that another method to summarize the indicators of beliefs to avoid multicollinearity is to employ factor analysis (FA) or principal components analysis (PCA). Latent class analysis has several advantages over FA and PCA in this context. First, because latent class analysis is grounded in a probability framework, we are able to calculate goodness-of-fit statistics that justify our model selection in a less arbitrary way than typically employed in FA and PCA. Second, use of FA and PCA requires us to assume that the observed indicators and the unobserved underlying factors are continuous and normally distributed. These methods can generate standardized scores but cannot generate types of beliefs. In our case, we assume that the answers to a series of yes or no questions are in fact dichotomous variables that, taken together, can characterize a belief system that is categorical rather than continuous.

\section{Conclusions}

Our results have demonstrated that culture in the form of religious beliefs does affect economic behavior. We have characterized the types of belief systems people hold using latent class analysis and find that individuals who have belief systems that could be characterized as being more spiritual, incorporating a belief of the soul but not necessarily a belief in God, are more likely to engage in pro-environment activities and have pro-environment attitudes. Importantly, our results show that only some combinations of beliefs generate higher likelihood of these outcomes relative to nonbelievers. That is, it is not being religious per se that matters but the system of religious beliefs the individual holds. 
The results also indicate that religious beliefs explain environmental action in addition to the effects of socio-demographic factors such as political identification, income, and education. Furthermore, we find a separate role for social capital associated with active membership in a church organization, however, we find no evidence that the impact of this kind of social capital differs from the effect of social capital accumulated through association with secular civic organizations.

These results have policy and methodological implications. When designing policies and programs to encourage pro-environment behavior and sustainability, it is important to understand how values and traditions influence an individual's propensity to provide for the public good of natural and environmental resources conservation. Our results indicate that the type of personal religious beliefs individuals hold do matter. However, these beliefs systems are not unique to specific religious affiliations and we are unable to find robust statistically significant effects of religious affiliation and churchgoing. In addition, when we restrict the sample to those individuals who do not attend church once a week or more, we find that the posterior probabilities of class membership are still significant providing additional evidence that personal religious beliefs have importance independent of institutionalized religion. These findings suggest that relying on organized religion might not be an effective way to promote and implement proenvironment policies. Rather, decision makers who want to appeal to people's values to encourage pro-environment behavior might use broader-based initiatives that go beyond affiliations and denominations and attract individuals who hold belief systems consistent with pro-environment behavior.

This research also raises interesting questions regarding the measurement and use of social and cultural values. Researchers must be careful with untested assumptions regarding how one or more indicators of culture can summarize the heterogeneity in the population. Our results indicate that there is substantial variability in religious beliefs, even in a sample of relatively homogenous OECD regions, and that applying a methodology to separate out heterogeneous populations provides results that are substantively richer than relying on standard approaches. 
Table 1: Descriptive Statistics

\begin{tabular}{|c|c|c|c|}
\hline Variable & Observations & Mean & Std. Dev. \\
\hline \multicolumn{4}{|l|}{ Religious Indicators } \\
\hline GOD (=1 if believe in God) & 11248 & .83 & .38 \\
\hline LIFE (=1 if believe in life after death) & 11248 & .62 & .48 \\
\hline SOUL (=1 if believe people have a soul) & 11248 & .79 & .41 \\
\hline DEVIL (=1 if believe the Devil exists) & 11248 & .44 & .49 \\
\hline HELL (=1 if believe in hell) & 11248 & .40 & .49 \\
\hline HEAVEN (=1 if believe in heaven) & 11248 & .60 & .48 \\
\hline SIN (=1 if believe in sin) & 11248 & .64 & .48 \\
\hline $\begin{array}{l}\text { IMPORTANT (= } 1 \text { if religion very important in one’s } \\
\text { life) }\end{array}$ & 11248 & .56 & .50 \\
\hline \multicolumn{4}{|l|}{ Pro-Environment Behaviors and Attitude } \\
\hline PRODUCT (=1 if use env. friendly products) & 11248 & .67 & .47 \\
\hline RECYCLE (=1 if recycle) & 11248 & .75 & .43 \\
\hline CONTRIBUTE (=1 if contribute to env. group) & 11248 & .18 & .38 \\
\hline $\begin{array}{l}\text { PROTECT (=1 if favor env. protection over } \\
\text { economic growth) }\end{array}$ & 9704 & .56 & .49 \\
\hline \multicolumn{4}{|l|}{ Religious Controls } \\
\hline $\begin{array}{l}\text { ACTIVE ( }=1 \text { if an active member of a church or } \\
\text { religious organization) }\end{array}$ & 11231 & .25 & .43 \\
\hline $\begin{array}{l}\text { CHURCHGOER (= } 1 \text { if attend religious services } \\
\text { once a week or more, apart from weddings, funerals } \\
\text { and christenings) }\end{array}$ & 11183 & .25 & .43 \\
\hline Catholic & 11173 & .47 & .50 \\
\hline Protestant & 11173 & .30 & .46 \\
\hline Orthodox and Jewish & 11173 & .011 & .105 \\
\hline Muslim & 11173 & .005 & .073 \\
\hline Other Affiliation & 11173 & .046 & .21 \\
\hline No Affiliation & 11173 & .17 & .37 \\
\hline \multicolumn{4}{|l|}{ Socio-Demographic Controls } \\
\hline FEMALE & 11233 & .52 & .50 \\
\hline AGE & 11084 & 42.90 & 17.06 \\
\hline CIVIC [Median] & 10941 & $3.49[4]$ & 1.70 \\
\hline POLITICAL [Median] & 10131 & $.98[1]$ & 1.08 \\
\hline $\begin{array}{l}\text { RIGHT (political self-placement, = } 1 \text { if extreme left, } \\
=10 \text { if extreme right) [Median] }\end{array}$ & 9781 & $5.24[5]$ & 2.03 \\
\hline GROUPS & 11176 & .72 & 1.02 \\
\hline Income1 (=1 if lowest income quintile) & 9514 & .19 & .39 \\
\hline Income2 (=1 if second income quintile) & 9514 & .29 & .46 \\
\hline Income3 (=1 if third income quintile) & 9514 & .24 & .42 \\
\hline Income4 (=1 if fourth income quintile) & 9514 & .16 & .36 \\
\hline Income5 (=1 if highest income quintile) & 9514 & .11 & .31 \\
\hline Education1 ( = 1 if high school not completed) & 10855 & .15 & .36 \\
\hline Education2 (= 1 if complete high school education) & 10855 & .36 & .48 \\
\hline Education3 ( = 1 if complete secondary education) & 10855 & .35 & .48 \\
\hline Education4 ( = 1 if university-level education) & 10855 & .14 & .34 \\
\hline
\end{tabular}


Table 2: Latent Class Models Fit Statistics

\begin{tabular}{|c|c|c|c|c|}
\hline & Log-Likelihood & BIC(LL) & Parameters & $\begin{array}{c}\text { Bootstrap p-value } \\
\text { of Pearson } \\
\text { statistic } \\
\text { (Std. Dev.) }\end{array}$ \\
\hline 1-Class & -49376.15 & 98854.90 & 11 & $<.001$ \\
\hline 2- Class & -40386.01 & 80958.58 & 20 & $<.001$ \\
\hline 3- Class & -39334.20 & 78938.92 & 29 & $<.001$ \\
\hline 4- Class & -39063.01 & 78480.49 & 38 & $<.001$ \\
\hline 5- Class & -38955.47 & 78349.34 & 47 & $<.001$ \\
\hline 6- Class & -38877.96 & 78278.29 & 56 & $<.001$ \\
\hline 7- Class & -38813.62 & 78233.55 & 65 & $<.001$ \\
\hline 8- Class & -38784.93 & 78260.13 & 74 & $<.001$ \\
\hline 9- Class & -38767.52 & 78309.26 & 83 & $<.001$ \\
\hline 10- Class & -38754.04 & 78366.24 & 92 & $.016(.0056)$ \\
\hline 11- Class & $-\mathbf{3 8 7 3 8 . 0 1}$ & $\mathbf{7 8 4 1 8 . 1 4}$ & $\mathbf{1 0 1}$ &. $\mathbf{2 1 2}(.0183)$ \\
\hline 12- Class & -38729.61 & 78485.29 & 110 & $.112(.0141)$ \\
\hline 13- Class & -38720.58 & 78551.18 & 119 & $.098(.0133)$ \\
\hline 14- Class & -38712.55 & 78619.08 & 128 & $.614(.0218)$ \\
\hline
\end{tabular}


Table 3: Probability Structure of Eleven Class Model

\begin{tabular}{|c|c|c|c|c|c|c|c|c|c|c|c|}
\hline & Class 1 & Class 2 & Class 3 & Class 4 & Class 5 & Class 6 & Class 7 & Class 8 & Class 9 & Class 10 & Class 11 \\
\hline Class Size & .363 & .131 & .094 & .122 & .104 & .084 & .063 & .011 & .015 & .009 & .004 \\
\hline \multicolumn{12}{|l|}{ Indicators } \\
\hline God & 0.999 & 0.963 & 0.148 & 0.998 & 0.309 & 0.918 & 0.974 & 0.886 & 0.725 & 0.999 & 0.660 \\
\hline After & 0.949 & 0.685 & 0.022 & 0.837 & 0.251 & 0.145 & 0.007 & 0.867 & 0.572 & 0.424 & 0.783 \\
\hline Soul & 0.996 & 0.999 & 0.013 & 0.937 & 0.999 & 0.018 & 0.628 & 0.965 & 0.979 & 0.739 & 0.466 \\
\hline Devil & 0.875 & 0.065 & 0.013 & 0.425 & 0.0002 & 0.076 & 0.361 & 0.469 & 0.892 & 0.017 & 0.215 \\
\hline Hell & 0.905 & 0.021 & 0.008 & 0.070 & 0.005 & 0.016 & 0.189 & 0.582 & 0.079 & 0.938 & 0.968 \\
\hline Heaven & 0.991 & 0.370 & 0.011 & 0.844 & 0.043 & 0.169 & 0.600 & 0.984 & 0.209 & 0.883 & 0.422 \\
\hline Sin & 0.982 & 0.342 & 0.109 & 0.859 & 0.253 & 0.221 & 0.996 & 0.669 & 0.623 & 0.772 & 0.395 \\
\hline Imp & 0.866 & 0.471 & 0.057 & 0.801 & 0.043 & 0.382 & 0.545 & 0.014 & 0.027 & 0.896 & 0.559 \\
\hline
\end{tabular}

Class 1: "Strong believers," very high response probabilities on all indicators.

Class 2: Very high probabilities of believing in God and the soul and high probability of belief in life after death.

Class 3: Secular class, all response probabilities are very low.

Class 4: Very high probabilities except for belief in Hell and the Devil.

Class 5: Very high probability of believing in the soul.

Class 6: Very high probabilities of believing in God.

Class 7: High probabilities of believing in God and sin. Medium probability of believing in the soul and stating religion is important.

Class 8: Very high probabilities for all beliefs except for belief in Hell and the Devil, with medium probabilities, and stating religion is important very low probability.

Class 9: Very high probabilities of belief in the soul and the Devil. High probabilities of belief in God and sin.

Class 10: Very high and high probabilities except for belief in the Devil and life after death.

Class 11: Very high probability of believing in Hell; high probabilities of believing in God and life after death. 
Table 4: Base Probit Models

\begin{tabular}{|c|c|c|c|c|}
\hline & $(1)$ & (2) & (3) & (4) \\
\hline & PRODUCT & RECYCLE & CONTRIBUTE & PROTECT \\
\hline \multirow[t]{2}{*}{ ActiveChurch } & 0.0623 & $0.1276^{* * *}$ & $0.0695 * *$ & 0.0505 \\
\hline & $(0.0504)$ & $(0.0325)$ & $(0.0351)$ & $(0.0536)$ \\
\hline \multirow[t]{2}{*}{ Churchgoer } & -0.0148 & 0.0860 & -0.0508 & 0.1064 \\
\hline & $(0.0591)$ & $(0.0683)$ & $(0.0424)$ & $(0.0702)$ \\
\hline \multirow[t]{2}{*}{ Catholic } & 0.0463 & -0.0933 & 0.0683 & -0.1058 \\
\hline & $(0.0691)$ & $(0.0826)$ & $(0.0928)$ & $(0.0918)$ \\
\hline \multirow[t]{2}{*}{ Protestant } & 0.0542 & -0.0292 & 0.0250 & -0.0432 \\
\hline & $(0.0634)$ & $(0.0857)$ & $(0.0670)$ & $(0.0628)$ \\
\hline \multirow[t]{2}{*}{ Muslim } & $0.4450 *$ & -0.1918 & 0.2683 & $0.5523 * *$ \\
\hline & $(0.2287)$ & $(0.2111)$ & $(0.1753)$ & $(0.2534)$ \\
\hline \multirow[t]{2}{*}{ OtherJC } & 0.0723 & 0.1325 & $0.2771^{* * *}$ & 0.1207 \\
\hline & $(0.3816)$ & $(0.3354)$ & $(0.1031)$ & $(0.2392)$ \\
\hline \multirow[t]{2}{*}{ OtherDenom } & -0.0130 & $-0.1976^{*}$ & 0.0071 & $-0.2184^{* *}$ \\
\hline & $(0.0771)$ & $(0.1015)$ & $(0.0900)$ & $(0.0982)$ \\
\hline \multirow[t]{2}{*}{ Age } & $0.0233^{* * *}$ & $0.0151^{* *}$ & 0.0067 & -0.0118 \\
\hline & $(0.0065)$ & $(0.0063)$ & $(0.0076)$ & $(0.0086)$ \\
\hline \multirow[t]{2}{*}{ Age2 } & $-0.0003^{* * *}$ & $-0.0002 * * *$ & -0.0000 & 0.0001 \\
\hline & $(0.0001)$ & $(0.0001)$ & $(0.0001)$ & $(0.0001)$ \\
\hline \multirow[t]{2}{*}{ Female } & $0.4333^{* * *}$ & $0.2099 * * *$ & $0.1010^{* *}$ & $0.0841^{* *}$ \\
\hline & $(0.0409)$ & $(0.0585)$ & $(0.0477)$ & $(0.0361)$ \\
\hline \multirow[t]{2}{*}{ Civic } & $0.0543^{* * *}$ & $0.0390 * * *$ & -0.0088 & 0.0107 \\
\hline & $(0.0116)$ & $(0.0101)$ & $(0.0122)$ & $(0.0165)$ \\
\hline \multirow[t]{2}{*}{ Political } & $0.1852 * * *$ & $0.1293^{* * *}$ & $0.1688^{* * *}$ & $0.1306 * * *$ \\
\hline & $(0.0234)$ & $(0.0284)$ & $(0.0195)$ & $(0.0197)$ \\
\hline \multirow[t]{2}{*}{ Right } & $-0.0278 * * *$ & $-0.0261^{* *}$ & $-0.0313 * * *$ & $-0.0413^{* * *}$ \\
\hline & $(0.0090)$ & $(0.0123)$ & $(0.0112)$ & $(0.0125)$ \\
\hline \multirow[t]{2}{*}{ Education1 } & $-0.4738 * * *$ & $-0.5403 * * *$ & $-0.3307 * * *$ & $-0.3358 * * *$ \\
\hline & $(0.1019)$ & $(0.1142)$ & $(0.0904)$ & $(0.0476)$ \\
\hline \multirow[t]{2}{*}{ Education2 } & $-0.2034 * * *$ & $-0.2426 * * *$ & $-0.2892 * * *$ & $-0.3134 * * *$ \\
\hline & $(0.0616)$ & $(0.0824)$ & $(0.0628)$ & $(0.0405)$ \\
\hline \multirow[t]{2}{*}{ Education3 } & -0.0711 & $-0.1447 *$ & $-0.1354 * *$ & $-0.2066 * * *$ \\
\hline & $(0.0573)$ & $(0.0739)$ & $(0.0591)$ & $(0.0439)$ \\
\hline \multirow[t]{2}{*}{ Inc1 } & $-0.1442 * *$ & $-0.1813^{* * *}$ & $-0.4259 * * *$ & -0.0791 \\
\hline & $(0.0583)$ & $(0.0445)$ & $(0.0945)$ & $(0.0791)$ \\
\hline \multirow[t]{2}{*}{ Inc2 } & -0.0524 & -0.0338 & $-0.3034 * * *$ & 0.0103 \\
\hline & $(0.0474)$ & $(0.0558)$ & $(0.0834)$ & $(0.0828)$ \\
\hline \multirow[t]{2}{*}{ Inc3 } & 0.0579 & $\begin{array}{l}-0.0239 \\
\end{array}$ & $-0.2411 * * *$ & 0.0544 \\
\hline & $(0.0640)$ & $(0.0787)$ & $(0.0635)$ & $(0.0777)$ \\
\hline \multirow[t]{2}{*}{ Inc4 } & -0.0302 & -0.0373 & $-0.1524 *$ & 0.0057 \\
\hline & $(0.0674)$ & $(0.0614)$ & $(0.0823)$ & (0.0595) \\
\hline \multirow[t]{2}{*}{ Constant } & $-0.4871 * *$ & 0.2641 & $-0.9929 * * *$ & $0.6701^{* * *}$ \\
\hline & $(0.2008)$ & $(0.2364)$ & $(0.1892)$ & $(0.2029)$ \\
\hline $\begin{array}{l}\text { Log } \\
\text { Pseudolikelihood }\end{array}$ & -3858.79 & -3304.07 & -3439.23 & -4259.21 \\
\hline BIC & 7824.39 & 6714.94 & 6985.26 & 8623.91 \\
\hline Observations & 7339 & 7339 & 7339 & 6574 \\
\hline
\end{tabular}

Robust standard errors in parentheses; * significant at $10 \%$; ** significant at $5 \%$; *** significant at $1 \%$; the models include country dummy variables 
Table 5: Probit Models Adding Posterior Probabilities of Latent Classes (omitted class is secular class)

\begin{tabular}{|c|c|c|c|c|}
\hline & $(1)$ & $(2)$ & (3) & $(4)$ \\
\hline & PRODUCT & RECYCLE & CONTRIBUTE & PROTECT \\
\hline \multirow[t]{2}{*}{ Class 1} & $0.1787 * *$ & 0.1427 & 0.0417 & 0.0587 \\
\hline & $(0.0814)$ & $(0.0886)$ & $(0.0840)$ & $(0.0652)$ \\
\hline \multirow[t]{2}{*}{ Class 2} & $0.2702 * * *$ & $0.3106 * * *$ & $0.1485^{*}$ & $0.2912 * * *$ \\
\hline & $(0.0773)$ & $(0.1065)$ & $(0.0855)$ & $(0.0626)$ \\
\hline \multirow[t]{2}{*}{ Class 4} & $0.4423 * * *$ & $0.1930^{*}$ & $0.1374 * * *$ & $0.1857^{*}$ \\
\hline & $(0.1113)$ & $(0.1163)$ & $(0.0529)$ & $(0.0953)$ \\
\hline \multirow[t]{2}{*}{ Class 5} & $0.2308^{* *}$ & $0.1581^{* *}$ & 0.1154 & $0.1101^{*}$ \\
\hline & $(0.0967)$ & $(0.0693)$ & (0.0928) & $(0.0597)$ \\
\hline \multirow[t]{2}{*}{ Class 6} & $0.2302 * * *$ & 0.0968 & 0.1766 & 0.0718 \\
\hline & $(0.0803)$ & $(0.1684)$ & $(0.1333)$ & $(0.0913)$ \\
\hline \multirow[t]{2}{*}{ Class 7} & -0.0749 & 0.0945 & $0.3045 * * *$ & 0.1037 \\
\hline & $(0.1039)$ & $(0.0953)$ & $(0.0946)$ & $(0.1066)$ \\
\hline \multirow[t]{2}{*}{ Class 8} & -0.1621 & 0.1294 & 0.2303 & -0.2699 \\
\hline & $(0.2594)$ & $(0.1891)$ & $(0.2858)$ & $(0.2381)$ \\
\hline \multirow[t]{2}{*}{ Class 9} & 0.1117 & 0.3096 & -0.0415 & 0.0883 \\
\hline & $(0.1788)$ & $(0.2531)$ & $(0.2036)$ & $(0.2009)$ \\
\hline \multirow[t]{2}{*}{ Class 10} & $-0.3674 *$ & 0.2418 & 0.0906 & 0.0078 \\
\hline & $(0.1989)$ & $(0.3034)$ & $(0.1998)$ & $(0.2073)$ \\
\hline \multirow[t]{2}{*}{ Class 11} & 0.2342 & -0.2141 & $0.5037^{*}$ & -0.1012 \\
\hline & $(0.3923)$ & $(0.3393)$ & $(0.2774)$ & $(0.1604)$ \\
\hline \multirow[t]{2}{*}{ ActiveChurch } & 0.0504 & $0.1213^{* * *}$ & $0.0793^{* *}$ & 0.0448 \\
\hline & $(0.0465)$ & $(0.0347)$ & $(0.0360)$ & $(0.0502)$ \\
\hline \multirow[t]{2}{*}{ Churchgoer } & -0.0269 & 0.0936 & -0.0254 & 0.1260 \\
\hline & $(0.0578)$ & $(0.0718)$ & $(0.0456)$ & $(0.0818)$ \\
\hline \multirow[t]{2}{*}{ Catholic } & 0.0137 & -0.1251 & 0.0508 & -0.1252 \\
\hline & $(0.0683)$ & $(0.0820)$ & $(0.0997)$ & $(0.0832)$ \\
\hline \multirow[t]{2}{*}{ Protestant } & 0.0334 & -0.0536 & 0.0047 & -0.0635 \\
\hline & $(0.0609)$ & $(0.0815)$ & $(0.0708)$ & $(0.0518)$ \\
\hline \multirow[t]{2}{*}{ Muslim } & $0.4268 *$ & -0.2278 & 0.2544 & $0.5441^{* *}$ \\
\hline & $(0.2302)$ & $(0.2261)$ & $(0.1899)$ & $(0.2618)$ \\
\hline \multirow[t]{2}{*}{ OtherJC } & 0.0601 & 0.1260 & $0.2495^{* *}$ & 0.1098 \\
\hline & $(0.3475)$ & $(0.3402)$ & $(0.1014)$ & $(0.2269)$ \\
\hline \multirow[t]{2}{*}{ OtherDenom } & -0.0434 & $-0.2181^{* *}$ & -0.0090 & $-0.2286 * *$ \\
\hline & $(0.0749)$ & $(0.0947)$ & $(0.0989)$ & $(0.0897)$ \\
\hline \multirow[t]{2}{*}{ Constant } & $-0.6125^{* * *}$ & 0.1304 & $-1.0991 * * *$ & $0.5769 * * *$ \\
\hline & $(0.1926)$ & $(0.2263)$ & $(0.1986)$ & $(0.2036)$ \\
\hline $\begin{array}{l}\text { Log } \\
\text { Pseudolikelihood }\end{array}$ & -3840.03 & -3295.49 & -3432.68 & -4247.70 \\
\hline BIC & 7786.87 & 6697.79 & 6972.16 & 8600.90 \\
\hline Observations & 7339 & 7339 & 7339 & 6574 \\
\hline
\end{tabular}

Robust standard errors in parentheses; * significant at 10\%; ** significant at 5\%; *** significant at $1 \%$; the models include country dummy variables and the controls in Table 1. 
Table 6: Probit Models Adding Posterior Probabilities of Latent Classes (omitted class is secular class) for CHURCHGOER $=0$

\begin{tabular}{|c|c|c|c|c|}
\hline & $(1)$ & $(2)$ & (3) & (4) \\
\hline & PRODUCT & RECYCLE & CONTRIBUTE & PROTECT \\
\hline \multirow[t]{2}{*}{ Class 1} & $0.1760^{* *}$ & 0.0914 & 0.1197 & -0.0144 \\
\hline & $(0.0880)$ & $(0.1056)$ & $(0.0751)$ & $(0.0558)$ \\
\hline \multirow[t]{2}{*}{ Class 2} & $0.2617 * * *$ & $0.2760 * *$ & $0.1455^{*}$ & $0.3027 * * *$ \\
\hline & $(0.0855)$ & $(0.1161)$ & $(0.0781)$ & $(0.0738)$ \\
\hline \multirow[t]{2}{*}{ Class 4} & $0.5243 * * *$ & 0.1626 & $0.1845 * * *$ & $0.2168^{*}$ \\
\hline & $(0.1189)$ & $(0.1101)$ & $(0.0646)$ & $(0.1263)$ \\
\hline \multirow[t]{2}{*}{ Class 5} & $0.2388 * *$ & $0.1735 * *$ & 0.1195 & 0.0973 \\
\hline & $(0.0971)$ & $(0.0693)$ & $(0.0921)$ & $(0.0607)$ \\
\hline \multirow[t]{2}{*}{ Class 6} & $0.2516 * * *$ & 0.0796 & 0.2167 & 0.0522 \\
\hline & $(0.0874)$ & $(0.1864)$ & $(0.1499)$ & $(0.1137)$ \\
\hline \multirow[t]{2}{*}{ Class 7} & -0.1228 & 0.0760 & $0.2557 * *$ & 0.0248 \\
\hline & $(0.0950)$ & $(0.1207)$ & $(0.1101)$ & $(0.0881)$ \\
\hline \multirow[t]{2}{*}{ Class 8} & -0.1577 & 0.2489 & 0.1793 & -0.1863 \\
\hline & $(0.2771)$ & $(0.2056)$ & $(0.3018)$ & $(0.2436)$ \\
\hline \multirow[t]{2}{*}{ Class 9} & 0.0688 & 0.2650 & -0.0079 & 0.1883 \\
\hline & $(0.1969)$ & $(0.2887)$ & $(0.2181)$ & $(0.1789)$ \\
\hline \multirow[t]{2}{*}{ Class 10} & $-0.3758 *$ & 0.3774 & 0.2528 & 0.0694 \\
\hline & $(0.2165)$ & $(0.3688)$ & $(0.2645)$ & $(0.3191)$ \\
\hline \multirow[t]{2}{*}{ Class 11} & 0.3138 & 0.0040 & $0.8304 * * *$ & -0.1962 \\
\hline & $(0.3694)$ & $(0.5780)$ & $(0.2177)$ & $(0.2227)$ \\
\hline \multirow[t]{2}{*}{ ActiveChurch } & 0.0649 & 0.0851 & 0.0115 & -0.0600 \\
\hline & $(0.0673)$ & $(0.0822)$ & $(0.0637)$ & $(0.0466)$ \\
\hline \multirow[t]{2}{*}{ Catholic } & -0.0220 & $-0.1581^{*}$ & 0.0143 & -0.0996 \\
\hline & $(0.0711)$ & $(0.0914)$ & $(0.1012)$ & $(0.0927)$ \\
\hline \multirow[t]{2}{*}{ Protestant } & 0.0080 & -0.0371 & -0.0048 & -0.0640 \\
\hline & $(0.0858)$ & $(0.0963)$ & $(0.0829)$ & $(0.0611)$ \\
\hline \multirow[t]{2}{*}{ Muslim } & 0.3033 & -0.2862 & 0.3334 & $0.7571^{* *}$ \\
\hline & $(0.4554)$ & $(0.3405)$ & $(0.2404)$ & $(0.3086)$ \\
\hline \multirow[t]{2}{*}{ OtherJC } & 0.0822 & 0.5193 & 0.2174 & 0.2028 \\
\hline & $(0.4017)$ & $(0.3871)$ & $(0.1723)$ & $(0.2709)$ \\
\hline \multirow[t]{2}{*}{ OtherDenom } & 0.0497 & -0.1010 & 0.0291 & -0.1356 \\
\hline & $(0.0920)$ & $(0.1585)$ & $(0.1489)$ & $(0.1439)$ \\
\hline \multirow[t]{2}{*}{ Constant } & $-0.4751 * *$ & 0.2113 & $-1.0088 * * *$ & $1.1579 * * *$ \\
\hline & $(0.2414)$ & $(0.2576)$ & $(0.2279)$ & $(0.1341)$ \\
\hline $\begin{array}{l}\text { Log } \\
\text { Pseudolikelihood }\end{array}$ & -2871.96 & -2500.99 & -2645.44 & -3263.25 \\
\hline BIC & 5847.48 & 5105.53 & 5394.43 & 6628.85 \\
\hline Observations & 5594 & 5594 & 5594 & 5062 \\
\hline
\end{tabular}

Robust standard errors in parentheses; * significant at 10\%; ** significant at 5\%; *** significant at $1 \%$; the models include country dummy variables and the controls in Table 1 (except CHURCHGOER). 
Table 7: Probit Models Adding Posterior Probabilities of Latent Classes and GROUPS (omitted class is secular class)

\begin{tabular}{|c|c|c|c|c|}
\hline & $(1)$ & $(2)$ & (3) & (4) \\
\hline & PRODUCT & RECYCLE & CONTRIBUTE & PROTECT \\
\hline \multirow[t]{2}{*}{ Class 1} & $0.1868^{* *}$ & 0.1519* & 0.0509 & 0.0546 \\
\hline & $(0.0809)$ & $(0.0902)$ & $(0.0869)$ & $(0.0656)$ \\
\hline \multirow[t]{2}{*}{ Class 2} & $0.2738 * * *$ & $0.3126 * * *$ & 0.1292 & $0.2808^{* * *}$ \\
\hline & $(0.0778)$ & $(0.1063)$ & $(0.0806)$ & $(0.0643)$ \\
\hline \multirow[t]{2}{*}{ Class 4} & $0.4411^{* * *}$ & 0.1832 & $0.1265 * *$ & $0.1769 *$ \\
\hline & $(0.1075)$ & $(0.1149)$ & $(0.0500)$ & $(0.0940)$ \\
\hline \multirow[t]{2}{*}{ Class 5} & $0.2270^{* *}$ & $0.1416^{*}$ & 0.1097 & $0.1067^{*}$ \\
\hline & $(0.0959)$ & $(0.0745)$ & $(0.0941)$ & $(0.0604)$ \\
\hline \multirow[t]{2}{*}{ Class 6} & $0.2380 * * *$ & 0.1026 & 0.1701 & 0.0712 \\
\hline & $(0.0781)$ & $(0.1665)$ & $(0.1269)$ & $(0.0922)$ \\
\hline \multirow[t]{2}{*}{ Class 7} & -0.0839 & 0.0811 & $0.2860 * * *$ & 0.0969 \\
\hline & $(0.1050)$ & $(0.0965)$ & $(0.0889)$ & $(0.1044)$ \\
\hline \multirow[t]{2}{*}{ Class 8} & -0.1631 & 0.1284 & 0.2658 & -0.2547 \\
\hline & $(0.2578)$ & $(0.1882)$ & $(0.2884)$ & $(0.2410)$ \\
\hline \multirow[t]{2}{*}{ Class 9} & 0.1039 & 0.3162 & -0.0112 & 0.1022 \\
\hline & $(0.1904)$ & $(0.2531)$ & $(0.2142)$ & $(0.2051)$ \\
\hline \multirow[t]{2}{*}{ Class 10} & $-0.3643^{*}$ & 0.2348 & 0.0658 & -0.0045 \\
\hline & $(0.2192)$ & $(0.2819)$ & $(0.2438)$ & $(0.2029)$ \\
\hline \multirow[t]{2}{*}{ Class 11} & 0.1841 & -0.2668 & $0.4443^{*}$ & -0.0960 \\
\hline & $(0.3876)$ & $(0.3571)$ & $(0.2587)$ & $(0.1720)$ \\
\hline \multirow[t]{2}{*}{ ActiveChurch } & 0.0122 & $0.0892 * * *$ & 0.0054 & 0.0395 \\
\hline & $(0.0464)$ & $(0.0345)$ & $(0.0319)$ & $(0.0532)$ \\
\hline \multirow[t]{2}{*}{ Churchgoer } & -0.0160 & 0.0972 & -0.0159 & 0.1203 \\
\hline & $(0.0582)$ & $(0.0723)$ & $(0.0448)$ & $(0.0848)$ \\
\hline \multirow[t]{2}{*}{ Catholic } & 0.0153 & -0.1180 & 0.0478 & -0.1269 \\
\hline & $(0.0716)$ & $(0.0869)$ & $(0.1018)$ & $(0.0842)$ \\
\hline \multirow[t]{2}{*}{ Protestant } & 0.0238 & -0.0681 & -0.0071 & -0.0687 \\
\hline & $(0.0621)$ & $(0.0808)$ & $(0.0697)$ & $(0.0509)$ \\
\hline \multirow[t]{2}{*}{ Muslim } & $0.4472 *$ & -0.2156 & 0.3145 & $0.5447 * *$ \\
\hline & $(0.2288)$ & $(0.2200)$ & $(0.1945)$ & $(0.2623)$ \\
\hline \multirow[t]{2}{*}{ OtherJC } & 0.0467 & 0.1063 & $0.2226 * *$ & 0.1034 \\
\hline & $(0.3475)$ & $(0.3374)$ & $(0.1096)$ & $(0.2252)$ \\
\hline \multirow[t]{2}{*}{ OtherDenom } & -0.0357 & $-0.2243 * *$ & -0.0616 & $-0.2322 * *$ \\
\hline & $(0.0755)$ & $(0.0998)$ & $(0.0982)$ & $(0.0939)$ \\
\hline \multirow[t]{2}{*}{ GROUPS } & $0.0927 * * *$ & $0.0966 * * *$ & $0.1729 * * *$ & 0.0169 \\
\hline & $(0.0209)$ & $(0.0200)$ & $(0.0166)$ & $(0.0138)$ \\
\hline \multirow[t]{2}{*}{ Constant } & $-0.6724 * * *$ & 0.0760 & $-1.2094 * * *$ & $0.5793 * * *$ \\
\hline & $(0.1993)$ & $(0.2225)$ & $(0.1906)$ & $(0.1982)$ \\
\hline $\begin{array}{l}\text { Log } \\
\text { Pseudolikelihood }\end{array}$ & -3810.27 & -3263.69 & -3357.24 & -4223.76 \\
\hline BIC & 7727.29 & 6634.12 & 6821.23 & 8552.94 \\
\hline Observations & 7299 & 7299 & 7299 & 6538 \\
\hline
\end{tabular}

Robust standard errors in parentheses; * significant at 10\%; ** significant at 5\%; *** significant at $1 \%$; the models include country dummy variables and the controls in Table 1 . 
Table 8: Stacked Probit Models (of PRODUCT and RECYCLE) with Posterior Probabilities of Latent Classes (omitted class is secular class)

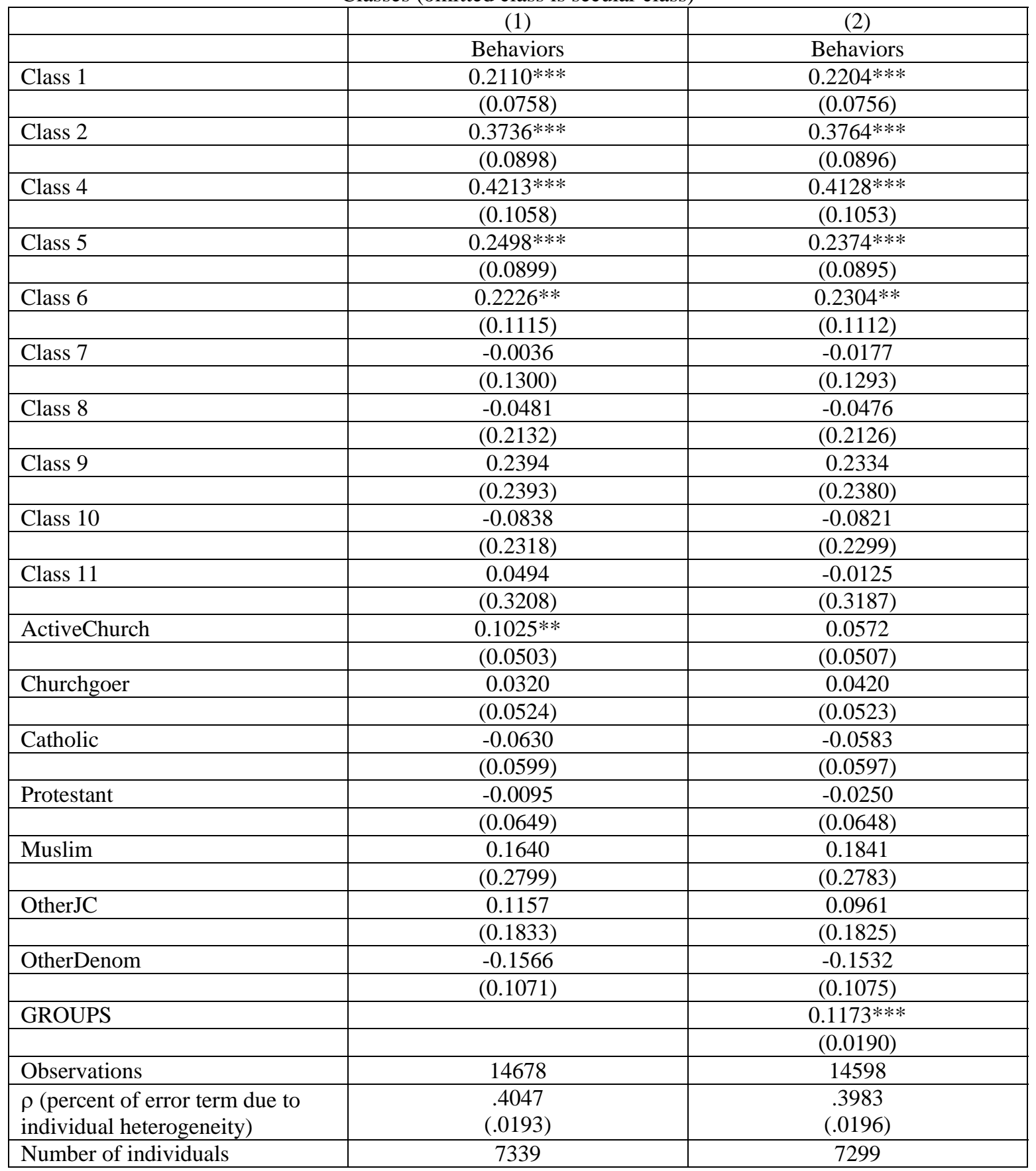

Standard errors in parentheses; * significant at $10 \%$; ** significant at 5\%; *** significant at $1 \%$; the model includes all other individual controls in Table 4, country dummy variables and individual random effects. 
Table 9: Using dummy variables to control for religious beliefs

\begin{tabular}{|c|c|c|c|c|c|c|c|c|}
\hline & (1) & $(2)$ & $(3)$ & $(4)$ & (5) & (6) & (7) & (8) \\
\hline & PRODUCT & PRODUCT & RECYCLE & RECYCLE & CONTRIBUTE & CONTRIBUTE & PROTECT & PROTECT \\
\hline \multirow[t]{2}{*}{ ActiveChurch } & 0.0565 & 0.0518 & $0.1199 * * *$ & $0.1266 * * *$ & $0.0649 *$ & 0.0578 & 0.0446 & 0.0389 \\
\hline & $(0.0496)$ & $(0.0480)$ & $(0.0338)$ & $(0.0340)$ & $(0.0362)$ & $(0.0390)$ & $(0.0528)$ & $(0.0492)$ \\
\hline \multirow[t]{2}{*}{ Churchgoer } & -0.0159 & -0.0284 & 0.0848 & 0.0860 & -0.0516 & -0.0479 & 0.1054 & 0.1149 \\
\hline & $(0.0591)$ & $(0.0553)$ & $(0.0681)$ & $(0.0740)$ & $(0.0430)$ & $(0.0505)$ & $(0.0698)$ & $(0.0811)$ \\
\hline \multirow[t]{2}{*}{ Catholic } & 0.0259 & 0.0158 & -0.1251 & $-0.1302^{*}$ & 0.0537 & 0.0536 & -0.1256 & -0.1314 \\
\hline & $(0.0690)$ & $(0.0682)$ & $(0.0781)$ & $(0.0772)$ & $(0.0985)$ & $(0.1019)$ & $(0.0898)$ & $(0.0858)$ \\
\hline \multirow[t]{2}{*}{ Protestant } & 0.0358 & 0.0424 & -0.0579 & -0.0487 & 0.0115 & 0.0084 & -0.0620 & -0.0618 \\
\hline & $(0.0609)$ & $(0.0609)$ & $(0.0805)$ & $(0.0789)$ & $(0.0719)$ & $(0.0728)$ & $(0.0562)$ & $(0.0533)$ \\
\hline \multirow[t]{2}{*}{ Muslim } & $0.4079 *$ & $0.4358^{*}$ & -0.2473 & -0.2189 & 0.2422 & 0.2355 & $0.5198 * *$ & $0.5406 * *$ \\
\hline & $(0.2257)$ & $(0.2293)$ & $(0.2222)$ & $(0.2209)$ & $(0.1803)$ & $(0.1965)$ & $(0.2582)$ & $(0.2659)$ \\
\hline \multirow[t]{2}{*}{ OtherJC } & 0.0627 & 0.0772 & 0.1175 & 0.1330 & $0.2675 * *$ & $0.2557 * *$ & 0.1097 & 0.1115 \\
\hline & $(0.3782)$ & $(0.3532)$ & $(0.3318)$ & $(0.3270)$ & $(0.1045)$ & $(0.1043)$ & $(0.2386)$ & $(0.2209)$ \\
\hline \multirow[t]{2}{*}{ OtherDenom } & -0.0311 & -0.0348 & $-0.2256 * *$ & $-0.2144 * *$ & -0.0052 & -0.0080 & $-0.2357 * *$ & $-0.2323 * *$ \\
\hline & $(0.0776)$ & $(0.0749)$ & $(0.0961)$ & $(0.0930)$ & $(0.0965)$ & $(0.1016)$ & $(0.0932)$ & $(0.0908)$ \\
\hline \multirow[t]{2}{*}{ BeliefGod } & $0.0775 * *$ & 0.0190 & $0.1178 *$ & 0.0924 & 0.0507 & 0.0724 & 0.0691 & 0.0562 \\
\hline & $(0.0381)$ & $(0.0412)$ & $(0.0669)$ & $(0.0689)$ & $(0.0525)$ & $(0.0677)$ & $(0.0445)$ & $(0.0455)$ \\
\hline \multirow[t]{2}{*}{ BeliefHell } & & $-0.1565 * *$ & & -0.0438 & & 0.0240 & & -0.1052 \\
\hline & & $(0.0647)$ & & $(0.0634)$ & & $(0.0618)$ & & $(0.0712)$ \\
\hline \multirow[t]{2}{*}{ BeliefHeaven } & & $-0.1564 * * *$ & & $-0.1336 * *$ & & -0.0734 & & $-0.1374 * * *$ \\
\hline & & $(0.0396)$ & & $(0.0556)$ & & $(0.0536)$ & & $(0.0448)$ \\
\hline \multirow[t]{2}{*}{ BeliefAfter } & & $0.1651 * * *$ & & $0.0950^{*}$ & & -0.0154 & & $0.1087 * * *$ \\
\hline & & $(0.0421)$ & & $(0.0513)$ & & $(0.0466)$ & & $(0.0384)$ \\
\hline \multirow[t]{2}{*}{ BeliefSoul } & & $0.0980 * *$ & & $0.1229 *$ & & 0.0370 & & $0.0993 *$ \\
\hline & & $(0.0424)$ & & $(0.0643)$ & & $(0.0618)$ & & $(0.0528)$ \\
\hline \multirow[t]{2}{*}{ BeliefDevil } & & 0.0288 & & -0.0303 & & -0.0296 & & -0.0321 \\
\hline & & $(0.0346)$ & & $(0.0546)$ & & $(0.0613)$ & & $(0.0593)$ \\
\hline \multirow[t]{2}{*}{ BeliefSin } & & $0.0957 * *$ & & $0.0649 *$ & & -0.0501 & & 0.0043 \\
\hline & & $(0.0411)$ & & $(0.0353)$ & & $(0.0501)$ & & $(0.0584)$ \\
\hline \multirow[t]{2}{*}{ RegImp } & & 0.0529 & & -0.0131 & & $0.0846^{*}$ & & $0.0852 * *$ \\
\hline & & $(0.0497)$ & & $(0.0459)$ & & $(0.0483)$ & & $(0.0369)$ \\
\hline Log Pseudolikelihood & -3857.61 & -3837.14 & -3301.72 & -3292.29 & -3438.73 & -3435.09 & -4258.16 & -4242.05 \\
\hline $\mathrm{BIC}$ & 7822.02 & 7781.09 & 6710.24 & 6691.40 & 6984.27 & 6976.99 & 8621.81 & 8589.57 \\
\hline Observations & 7339 & 7339 & 7339 & 7339 & 7339 & 7339 & 6574 & 6574 \\
\hline
\end{tabular}

Robust standard errors in parentheses; * significant at $10 \%$; ** significant at $5 \%$; ** significant at $1 \%$; the models include country dummy variables and the controls in Table 1. 


\section{References}

Anderson, Gary M., 1988, "Mr. Smith and the Preachers: The Economics of Religion in the Wealth of Nations” Journal of Political Economy, 96(5), 1066-1088.

Azzi, Corry and Ronald G. Ehrenberg, 1975, "Household Allocation of Time and Church Attendance,” Journal of Political Economy 83(2): 27-56.

Biels and Nilsson, 2005, "Religious Values and Environmental Concern: Harmony and Detachment,” Social Science Quarterly, 68(1): 178-191.

Biemer, Paul P., and Christopher Wiesen, 2002, "Measurement Error Evaluation of Self-reported Drug Use: A Latent Class Analysis of the US National Household Survey on Drug Abuse," Journal of the Royal Statistical Society: Series A (Statistics in Society), 165(1): 97-119.

Bishop, George, 1999, “Americans’ belief in God,” Public Opinion Quarterly, 63: 421-434.

Boxall, Peter C., and Wiktor .L. Adamowicz, 2002, "Understanding Heterogeneous Preferences in Random Utility Models: The Use of Latent Class Analysis,” Environmental and Resource Economics, 23(4): 421-446.

Brooks, Arthur C., 2003, “Religious Faith and Charitable Giving,” Policy Review 121: 39-50.

Brooks, Arthur C. and Gregory B. Lewis, 2001, “Giving, Volunteering, and Mistrusting Government,” Journal of Policy Analysis and Management 20(4): 765-769.

Clark, Andrew, Feabrice Etile, Fabien Postel-Vinay, Caludia Senik and karine Van der Straeten, 2005, "Heterogeneity in reported well-being: evidence from twelve European countries," Economic Journal 115: c118-c132.

Easterly, William and Ross Levine, 1997, “Africa’s Growth Tragedy: Policies and Ethnic Divisions,” Quarterly Journal of Economics 16(5): 563-76.

Easterly, William and Ross Levine, 2003, “Tropics, Germs, and Crops: How Endowments Influence Economic Development,” Journal of Monetary Economics 50: 3-39.

Glaeser, Edward L, Rafael La Porta, Florencio Lopez-de-Silanes, and Andrei Shleifer, 2004, “Do Institutions Cause Growth?” NBER Working Paper \#10568.

Greene, William H., and David A. Hensher, 2003, “A Latent Class Model for Discrete Choice Analysis: Contrasts with Mixed Logit,” Transportation Research Part B 37:681-698.

Greif, Avner, 1994, "Cultural Beliefs and the Organization of Society: A Historical and Theoretical Reflection on Collectivist and Individualist Societies,” Journal of Political Economy 5(102): 912-950. 
Guiso, Luigi, Paola Sapienza, and Luigi Zingales, 2006, "Does culture affect economic outcomes?” The Journal of Economic Perspectives, 20(2): 23-48.

Guiso, Luigi, Paola Sapienza, and Luigi Zingales, 2003, "People’s Opium? Religion and Economic Attitudes,” Journal of Monetary Economics 50(1): 225-82.

Iannaccone, Laurence, R., 1998, “Introduction to the Economics of Religion,” Journal of Economic Literature 36(3): 1465-1495.

Iyigun, Murat and Ann L. Owen, 2006, "Experiencing Change and the Evolution of Adaptive Skills: Implications for Growth” European Economic Review, 50(3): 565-579.

Knack, Stephen, and Philip Keefer, 1997, "Does Social Capital Have an Economic Payoff?,” Quarterly Journal of Economics, 112(4): 1251-88.

La Porta, Rafael, Florencio Lopez-de-Silanes, Andrei Shleifer, and Robert Vishny, 1999, "The Quality of Government,” Journal of Law, Economics and Organization 15(1): 222-279.

Magidson, Jay and Jeroen K. Vermunt, 2003, “Latent Class Models,” Tilburg University, mimeo.

McCleary, Rachel and Robert J. Barro, 2006, "Religion and Economy,” The Journal of Economic Perspectives, 20(2): 49-72.

Morey, Edward, Thacher, Jennifer, and Bill Breffle (2006): "Using Angler Characteristics and Attitudinal Data to Identify Environmental Preference Classes: A Latent-Class Model,” Environmental and Resource Economics 34(1): 91-115.

Owen, Ann L. and Julio Videras, 2006, “Civic Cooperation, Pro-Environment Attitudes, and Individual Behavior,” Ecological Economics 58(4): 814-829.

Patterson, Blossom H., Dayton, Mitchell C., Barry I. Graubard, 2002, "Latent Class Analysis of Complex Sample Survey Data: Application to Dietary Data," Journal of the American Statistical Association, 97(459): 721-29.

Provencher, Bill, and Richard C. Bishop, 2004: "Does Accounting for Preference Heterogeneity Improve the Forecasting of a Random Utility Model? A Case Study,” Journal of Environmental Economics and Management, 48(1): 793-810.

Putnam, Robert, 2000, Bowling Alone: The Collapse and Revival of American Community (New York: Simon and Schuster).

Scarpa, Riccardo, and Mara Thiene, 2005: "Destination Choice Models for Rock Climbing in the Northeastern Alps: A latent-Class Approach Based on Intensity of Preferences," Land Economics, 81(3): 426-444. 
Tabellini, Guido, 2005, "Culture and Institutions: Economic Development in the Regions of Europe,” CESifo Working Paper \#1492.

Temple, Jonathan and Paul A. Johnson, 1998, "Social Capability and Economic Growth,” Quarterly Journal of Economics 113(3): 965-990.

Weber, Max, 1930, Protestant Ethic and the Spirit of Capitalism, trans. T. Parsons (New York: Scribner and Sons).

White, Lynn, 1967: “The historical roots of our ecological crisis,” Science 155: 1203-1207.

Whitford, Andrew B. and Karen Wong, 2006, "Political and Social Foundations for Environmental Sustainability,” University of Georgia mimeo. 